\title{
Inherited Cardiomyopathies: From Genotype to Phenotype
}

\section{Marzia De Bortoli*}

Department of Biology, University of Padua, Italy

Inherited Cardiomyopathies are a set of heterogeneous heart muscle diseases which include for example Arrhythmogenic Cardiomyopathy (ACM), Hypertrophic Cardiomyopathy (HCM) and Dilated Cardiomyopathy (DCM). At broader level these cardiomyopathies are considered genetically and phenotypically distinct diseases, showing an autosomal-dominant inheritance with incomplete penetrance and variable expressivity [1]. In particular they are associated with an increased risk of heart failure, heart transplantation, malignant cardiac arrhythmias and stroke. Moreover, they are the most common causes of sudden cardiac death in the young and athletes $[2,3]$. Understanding the relationship between genotype and phenotype is fundamental for a better diagnosis and management of patients affected with inherited cardiomyopathies.

$\mathrm{ACM}$ is characterized by the progressive loss of ventricular cardiomyocytes with replacement by fibro-fatty tissue, predominantly in the right ventricle, triggering arrhythmia, heart failure and sudden cardiac death. Its prevalence is estimated at between 1:2000 and 1:5000. Most of the ACM causing mutations have been identified in genes encoding proteins of the intercalated disc, in particular in desmosomal proteins as for example desmoplakin (DSP), plakophilin-2 (PKP2) and desmoglein-2 (DSG2) [4]. HCM is characterized by unexplained cardiac hypertrophy of the left ventricle, cardiomyocyte disarray and fibrosis, leading to contractile dysfunction, heart failure, and sudden cardiac death. Its prevalence is of 1:500 in the general population. HCM is commonly described as a disease of the sarcomere and the majority of the causative mutations have been identified in the myosin-binding protein $\mathrm{C}$ (MYBPC3) gene and the $\beta$ myosin heavy chain (MYH7) gene [5]. A significant proportion of ACM and HCM patients resulted to carry compound or double mutations in their respectively associated genes, showing a more severe form of cardiomyopathy than family members harboring a single mutation $[6,7]$.

In the last 20 years, the increased knowledge of genetic causes and longitudinal follow-up of individuals affected with cardiomyopathies have demonstrated that in many cases there may be an overlap not only in phenotypical features but also in molecular etiology. Different mutations in the same gene were reported to cause different cardiomyopathies, for instance mutations in genes encoding for sarcomere proteins were reported to cause both HCM and DCM [8] and mutations in genes encoding for desmosomal proteins were reported to cause both ACM and DCM [8].

Even if, in the era of next generation sequencing with the huge number of identified sequence variants, it has become crucial the interpretation of the clinical significance of any single mutation, it must be considered that causative mutations are only the first step to understand the entire mechanism leading to the specific disease phenotype. It is becoming increasingly evident that the causative mutations identified in the patients affected with cardiomyopathy are often insufficient to predict the phenotype of other mutation carriers in the same family, whom could be asymptomatic, show minor signs of the disease or a more severe phenotype compared to the proband. There are numerous factors affecting gene expression and protein function that could modulate the effect of causative mutations on the cardiac phenotype. Modifier genes are one of the factors that may explain differences in the disease phenotype as for example expression, progression, severity, penetrance and age at onset. In order to improve diagnosis, prognosis and management of patients it will be necessary, in addition to the identification of the causative mutation, to understand the impact of modifier genes, epigenetic and environmental factors on the phenotype. The identification of very frequent founder mutations, as described in Italian (20\%) and Icelandic (58\%) HCM patients [9,10], provides a rare opportunity to assess the relationship between genotype and phenotype and could facilitate the identification of modifier factors involved in the disease. Patients with the same mutation eliminate the bias introduced by using subjects with different mutations, giving the possibility to discover modifier genes playing a significant role on the disease variability. In this way, it is possible to avoid the confounding effects due to the genetic heterogeneity of patients carrying different mutations which per se could be associated with a different expression of the cardiac phenotype. Identification of such modifier genes increases our understanding of the molecular components that affect the phenotypic variability in patients with inherited cardiomyopathies and thereby could improve the genetic based diagnosis, risk stratification, prognosis and enhance the implementation of preventive and therapeutic measures resulting in a more personalized health care and a subsequent life improvement of patients and their relatives.

\section{References}

1. Towbin JA (2014) Inherited cardiomyopathies. Circ J 78: 2347-2356.

2. Thiene G, Nava A, Corrado D, Rossi L, Pennelli N (1988) Right ventricular cardiomyopathy and sudden death in young people. N Engl J Med 318: 129133.

3. Maron BJ, Doerer JJ, Haas TS, TierneyDM, Mueller FO (2009). Sudden deaths in young competitive athletes: Analysis of 1866 deaths in the United States, 1980-2006. Circulation 119: 1085-1092.

4. Calore M, Lorenzon A, De Bortoli M, Poloni G, Rampazzo A (2015) Arrhythmogenic cardiomyopathy: A disease of intercalated discs. Cell Tissue Res 360: 491-500.

5. Ho CY, Charron P, Richard P, Girolami F, Van Spaendonck-Zwarts KY, et al. (2015) Genetic advances in sarcomeric cardiomyopathies: State of the art. Cardiovasc Res 105: 397-408

6. Bauce B, Nava A, Beffagna G, Basso C, Lorenzon A, et al. (2010) Multiple mutations in desmosomal proteins encoding genes in arrhythmogenic right ventricular cardiomyopathy/dysplasia. Heart Rhythm 7: 22-29.

7. Maron BJ, Maron MS, Semsarian C (2012) Double or compound sarcomere mutations in hypertrophic cardiomyopathy: A potential link to sudden death in the absence of conventional risk factors. Heart Rhythm 9: 57-63.

8. Teekakirikul P, Kelly MA, Rehm HL, Lakdawala NK, Funke BH (2013) Inherited cardiomyopathies: Molecular genetics and clinical genetic testing in the postgenomic era. J Mol Diagn 15: 158-170.

*Corresponding author: Marzia De Bortoli, Department of Biology, University of Padua, Italy, Tel: +390498276208; E-mail: marzia.debortoli@unipd.it

Received October 27, 2017; Accepted November 27, 2017; Published January 04, 2018

Citation: De Bortoli M (2017) Inherited Cardiomyopathies: From Genotype to Phenotype. J Clin Med Genomics 6: e104. doi: 10.4172/2472-128X.1000e104

Copyright: (c) 2018 De Bortoli M. This is an open-access article distributed under the terms of the Creative Commons Attribution License, which permits unrestricted use, distribution, and reproduction in any medium, provided the original author and source are credited. 
9. Calore C, De Bortoli M, Romualdi C, Lorenzon A, Angelini A, et al. (2015) A founder MYBPC3 mutation results in HCM with a high risk of sudden death after the fourth decade of life. J Med Genet 52: 338-347.
10. Adalsteinsdottir B, Teekakirikul P, Maron BJ, Burke MA, Gudbjartsson DF, et al . (2014) Nationwide study on hypertrophic cardiomyopathy in Iceland: evidence of a MYBPC3 founder mutation. Circulation 130: 1158-1167. 